MR ROBERT J.A.H. EENDEBAK (Orcid ID : 0000-0003-0769-5899)

Received Date : 20-Sep-2016

Revised Date : 24-Jan-2017

Accepted Date : 29-Jan-2017

Article type $\quad: 1$ Original Article - UK, Europe

\title{
Ethnic differences in male reproductive hormones and relationships with adiposity and insulin resistance in older men
}

Robert J.A.H. Eendebak M.Sc. ${ }^{1}$, Agnieszka Swiecicka M.D. ${ }^{1}$, Piotr S. Gromski Ph.D. ${ }^{2}$, Stephen R. Pye Ph.D. ${ }^{3}$, Terence W. O'Neill M.D. ${ }^{3}$, Alan Marshall Ph.D. ${ }^{4}$, Brian G. Keevil M.Sc. ${ }^{5}$, Gindo Tampubolon Ph.D. ${ }^{6}$, Royston Goodacre Ph.D. ${ }^{7}$, Frederick C.W. Wu M.D. ${ }^{1}$ and Martin K. Rutter M.D. ${ }^{8,9}$

${ }^{1}$ University of Manchester, Manchester Academic Health Sciences Centre, Faculty of Medical and Human Sciences, Institute of Human Development, Centre for Endocrinology and Diabetes, Andrology Research Unit

${ }^{2}$ University of Glasgow, School of Chemistry, Complex Chemical Systems Group

${ }^{3}$ Arthritis Research UK Centre for Epidemiology \& NIHR Manchester Musculoskeletal Biomedical Research Unit, The University of Manchester, Manchester Academic Health Science Centre, Manchester. UK

${ }^{4}$ University of St. Andrews, School of Geography and Geosciences, Department of Geography and Sustainable Development

${ }^{5}$ University South Manchester Hospital, Department of Clinical Biochemistry

${ }^{6}$ University of Manchester, Faculty of Humanities, Cathie Marsh Institute for Social Research

${ }^{7}$ University of Manchester, School of Chemistry, Manchester Institute for Biotechnology

${ }^{8}$ University of Manchester, Manchester Academic Health Sciences Centre, Central Manchester University Hospitals NHS Foundation Trust, Manchester Diabetes Centre

${ }^{9}$ University of Manchester, Faculty of Medical and Human Sciences, Institute of Human Development, Endocrinology and Diabetes Research Group

\section{Corresponding author and person to whom reprint requests should be addressed:}

Robert J.A.H. Eendebak M.Sc.

Andrology Research Unit

Centre for Endocrinology and Diabetes

Institute of Human Development

Faculty of Medical and Human Sciences

University of Manchester

Old St. Mary's Building

M13 9WL, United Kingdom

Phone: +44 161276 6295;

Fax: +44 161276 6363;

E-mail: roberteendebak@gmail.com

\section{Conflict of interest}

None

\section{Abbreviated title \\ Ethnic differences in HPT-axis function}

Disclosure statement: FCWW has acted as a consultant for Bayer-Schering, Eli Lilly and Besins Healthcare and also participated in advisory board meetings and lectured on their behalf. FCWW has received lecture fees from Bayer-Schering and Besins Healthcare. FCWW has received grant support (2010-2014) from Bayer Schering AG and Besins Healthcare. MKR has acted as a consultant for GSK, and also participated in advisory board meetings on their behalf. MKR has received lecture fees from MSD and grant support from

This article has been accepted for publication and undergone full peer review but has not been through the copyediting, typesetting, pagination and proofreading process, which may lead to differences between this version and the Version of Record. Please cite this article as doi: 10.1111/cen.13305

This article is protected by copyright. All rights reserved. 
Novo Nordisk, MSD and GSK.

\section{Abstract}

Objectives: To assess ethnic differences in male reproductive hormone levels and to determine if any differences are explained by adiposity, insulin resistance (IR), or comorbidities in older men.

Design: Multi-ethnic cross-sectional observational study.

Participants: Community dwelling middle-aged and elderly men residing in the U.K. aged 40-84 years of South Asian (SA; $n=180$ ), White European (WE; $n=328$ ) or African Caribbean (AC; $n=166)$ origin.

Observations: Measured testosterone $(T)$, calculated free $T(\mathrm{cFT}), \mathrm{SHBG}$, and LH in SA, WE and $A C$ men along with an assessment of body composition, IR, life-style factors and medical conditions.

Results: Age-adjusted mean T and cFT levels were lower in SA men when compared to WE and AC men (mean (SEM) T: SA: 14.0 \pm 0.4 ; WE: $17.1 \pm 0.3$; AC: $17.2 \pm 0.5 \mathrm{nmol} / \mathrm{L}, \mathrm{p}<0.001$; cFT: SA: $283 \pm 7$; WE: $313 \pm 5$; AC: $314 \pm 8 \mathrm{pmol} / \mathrm{L}, \mathrm{p}<0.006)$. Compared to WE and AC men, SA men had higher levels of body fat, IR, comorbidities and diabetes. After adjusting for body fat, IR and other confounders, $T$ levels in SA men remained lower than in WE men $(p=0.04)$ but ethnic differences in cFT became non-significant. LH levels were higher in SA than WE men in age-adjusted and fully-adjusted models.

Conclusions: T and cFT are lower in SA men than in WE and AC men. Whether ethnicspecific reference ranges for $\mathrm{T}$ and $\mathrm{cFT}$ might be appropriate in clinical practice requires further investigation. Ethnic differences in cFT, but not $\mathrm{T}$, appear to be, more readily, explained by ethnic differences in adiposity, thus providing insights into potential pathophysiological mechanisms.

This article is protected by copyright. All rights reserved. 


\section{Introduction}

Testosterone $(T)$ is critically important to men's health and is routinely measured to detect gonadal dysfunction. There is limited data comparing male reproductive hormone levels $(\mathrm{RH})$, such as $\mathrm{T}$, free $\mathrm{T}$, sex hormone-binding globulin (SHBG), and luteinizing hormone (LH) in different ethnic groups.

The largest previous study, involving 50 South Asian (SA) men, showed lower levels of total $T(T)$ and calculated free $T(\mathrm{cFT})$ in SA compared to White European (WE) and African Caribbean (AC) men ${ }^{1}$. However, in this study these ethnic differences did not persist after adjusting for age, insulin, SHBG, height and waist hip ratio. The results of this study may have been influenced by the relatively small sample size, statistical power, assay precision (immunoassay used), non-standardized time of serum sample collection, and unmeasured confounders such as diabetes therapies.

A large US-based study showed no ethnic differences in T or cFT between Caucasian ( $n=706)$, African American $(n=530)$ and Hispanic $(n=649)$ men and that relationships between these hormones and components of the metabolic syndrome were similar across these groups ${ }^{2}$. Although this important study had several strengths, it was limited because South Asian men were not included, $T$ was measured by radioimmunoassay and relationships between androgens and BMI were not assessed directly.

Ethnic differences in adiposity have been reported, such that SA men generally have more visceral fat compared to WE men ${ }^{3,4}$. Obesity can cause low $T$ via its negative impact on gonadotrophin secretion ${ }^{5-7}$, but the accompanying insulin resistance (IR) and decreased SHBG may also contribute to the low total $\mathrm{T}$ without similarly affecting $\mathrm{FT}^{8}$. It is unclear whether or how ethnic differences in adiposity could impact on assessment of $\mathrm{RH}$ in the diagnosis of hypogonadism. Other factors could also contribute to ethnic differences in $\mathrm{RH}$ including diabetes and IR (more common in SA men) ${ }^{9}$ and diabetes therapies which can influence $\mathrm{IR}^{10}$

Therefore, our aims were: 1) to compare $\mathrm{RH}$ in SA, WE and AC men; 2) to assess the influence of confounders, especially, body fat, IR and comorbidity burden, on any ethnic 
differences in $\mathrm{RH}$; and 3) to compare the relationship of $\mathrm{RH}$ with adiposity, as assessed by BMI, waist circumference (WC) or body fat (\%) across ethnic groups.

\section{Methods}

\section{Study design and participants}

The study population consisted of unselected community dwelling middle-aged and elderly men (mean \pm SD age: $59 \pm 12$ years) living in Greater Manchester, U.K. of SA $(n=180)$, WE $(n=328)$, or $A C(n=166)$ origin participating in the Human Serum Metabolome (HUSERMET) study as previously described ${ }^{11}$. Briefly, SA and AC men were recruited from the Central Manchester community. The WE men were the Manchester participants of the European Male Ageing Study (EMAS), which is a population-based observational study of male ageing $^{12,13,14}$. Ethnicity was determined based on the self-report of the country of origin of 3 grandparents, similar to a previous study ${ }^{1}$. Ethnicity could not be determined in a small proportion of men $(n=10)$ and some men had a different ethnic background than SA, WE or $A C(n=25)$.

\section{Inclusion and exclusion criteria}

From the 709 men in HUSERMET, participants were excluded from the present study if they reported use of medication affecting HPT-axis function, treatment for pituitary, testicular or adrenal disease ( $n=31$ men), or if their BMl exceeded $60 \mathrm{~kg} / \mathrm{m}^{2}$ ( $\mathrm{n}=2$ AC men). In addition, men with other or uncertain ethnic backgrounds were excluded ( $n=34$ men) leaving 642 men for analysis (flow chart, Figure 1).

\section{Clinical, anthropometric and male reproductive hormone measurements}

The presence of 1 or more comorbidities was determined based on self-reported presence or treatment for heart disease, stroke, hypertension, diabetes, bronchitis, cancer, kidney or liver disease. Poor health status was determined by how each participant rated his general health and included responses, such as 'fair' or 'poor'. Clinical symptoms were assessed 
according to definitions proposed in previous work from our research groups ${ }^{14}$. Physical activity (PA) was assessed by self-report and included responses on the Physical Activity Scale for the Elderly (PASE) $)^{15}$. Smoking status was classified as never, ex- and current smoker. Frequent alcohol intake was considered as alcohol intake $\geq 5$ days/week. Measurements of weight $(\mathrm{kg})$, height $(\mathrm{cm})$, waist $(\mathrm{cm})$, calf circumference $(\mathrm{cm})$, and body fat percentage (skin calipers) (\%) were made using standardized protocols described previously $^{12,13}$. Insulin resistance was determined by the homeostasis model assessment of insulin resistance $(\mathrm{HOMA}-\mathrm{IR}=\text { fasting insulin }[\mathrm{U} / \mathrm{mL}] \times \text { fasting glucose }[\mathrm{mmol} / \mathrm{L}] / 22.5)^{16}$.

Fasting venous blood samples were provided before 10:00 AM for T, sex hormonebinding globulin (SHBG), luteinizing hormone (LH), and albumin measurements. cFT was derived from T, SHBG and albumin measurements by the Vermeulen formula ${ }^{17,18}$. $T$ was analyzed via liquid-chromatography tandem mass spectrometry (LC-MS/MS $)^{19}$. SHBG and LH were determined via a modular E-170 immunoassay platform, as described previously ${ }^{6}$. Intra- and Inter-assay coefficients of variation (CVs) for these assays were: $\mathrm{T}, 4.0 \%$ and $5.6 \%$; SHBG, $1.7 \%$ and 3.2\%; LH, 1.9\% and 3.0\%, respectively. The lower limit of detection for the male reproductive hormones investigated was: T [0.50 nmol/L; $0.14 \mu \mathrm{g} / \mathrm{L}], \mathrm{cFT}[5.77$ pmol/L; $1.7 \mathrm{ng} / \mathrm{L}]$, SHBG [8.2 nmol/L], and LH [0.38 U/L].

\section{Statistical analysis}

Clinical characteristics are presented as mean \pm SEM for continuous parameters or number (percentage) values for binary parameters. Between-group comparisons were assessed using analysis of variance for continuous variables and Z-test for categorical variables. Univariate differences in T and cFT levels across body mass index (BMI) categories within ethnic groups were assessed using analysis of variance.

Age-adjusted and multivariable-adjusted mean \pm SEM $\mathrm{RH}$ were compared between the 3 ethnic groups. Covariates included age, frequent alcohol intake, smoking (current vs. never), body fat (\%), IR, and comorbidity burden ( $\geq 1$ comorbidities). Between-group comparisons were assessed using analysis of covariance.

This article is protected by copyright. All rights reserved. 
Linear regression was used to assess the relationships of $\mathrm{RH}$ (outcomes) with BMI, WC or body fat (\%) (predictors) and age-adjusted and fully-adjusted beta coefficients (95\% Cl) were depicted in forest plots (covariates: age, frequent alcohol intake, smoking (current vs never), IR and comorbidity burden ( $\geq 1$ comorbidities)).

Independent replication of the regression analyses was performed within the analytical sample via use of 5 -fold cross-validation ${ }^{20}$ and results are depicted as mean squared error values for each ethnic group. This allowed for an assessment of the robustness of observed relationships in the regression analyses. All analyses were performed using STATA 13 SE software (StataCorp. 2013. Stata Statistical Software: Release 13. College Station, TX: StataCorp LP.).

\section{Results}

\section{Clinical characteristics}

\section{South Asian men vs. White European men}

Compared with WE men, SA men were younger, shorter, with a higher percentage of body fat (but similar BMI) and had lower calf circumference values (Table 1). The prevalence of current smokers was higher in SA men, while self-reported frequent alcohol intake and PA were lower. SA men had higher glucose and IR, a higher prevalence of self-reported diabetes, a higher prevalence of poor health status and a higher burden of comorbidities. T and SHBG were lower, but cFT and LH similar, in SA men, when compared to WE men. In addition, SA men had a higher prevalence of decreased libido, limited walking, inability to bend, fatigue, loss of energy, and sadness, when compared to WE men (Table S1)

\section{South Asian men vs. African Caribbean men}

Compared with AC men, SA men were older, shorter and also displayed a higher percentage of body fat but had similar BMI values (Table 1). In SA men, the prevalence of current smoking, frequent alcohol intake and PA were lower. SA men had higher glucose levels and IR, more self-reported diabetes, poorer health status, and a higher burden of 
comorbidities. T, cFT and SHBG were lower, but LH was similar in SA men, when compared to AC men. In addition, SA men had a higher prevalence of decreased vigorous activity, limited walking, inability to bend, fatigue, and loss of energy, when compared to AC men (Table S1).

\section{African Caribbean men vs. White European men}

Compared with AC men, WE men were older and had higher WC but similar BMI. They had higher calf circumference, a lower prevalence of current smoking and a higher prevalence of frequent alcohol intake (Table 1). WE men had a lower prevalence of diabetes and better health status. cFT was lower and T, SHBG, and LH similar in WE men, when compared to AC men. In addition, WE men had a higher prevalence of decreased morning erections, erectile dysfunction, and decreased vigorous activity, when compared to AC men (Table S1).

Univariate relationships between body mass index (BMI) categories and testosterone levels across ethnic groups

In SA men, levels of $\mathrm{T}$ did not differ across BMl categories, while in WE men $\mathrm{T}$ levels differed in lean vs. overweight, lean vs. obese, and overweight vs. obese men. In AC men, T levels differed in lean vs. obese and overweight vs. obese men.

In SA men, levels of cFT did not differ across BMl categories, while in WE men cFT levels differed in lean vs. overweight, lean vs. obese, and overweight vs. obese men. In AC men, cFT levels differed in lean vs. obese and overweight vs. obese men (Table S2).

\section{Age-adjusted and multivariable-adjusted male reproductive hormone levels across ethnic groups}

South Asian men vs. White European men

Age-adjusted mean T, cFT and SHBG were lower, but LH levels were higher in SA men when compared to WE men (Table 2). After adjusting for age, frequent alcohol intake, smoking, \%body fat, IR and comorbidities, T levels remained lower and LH remained higher 
in SA men compared to WE men (Table 2 and Table S3).

\section{South Asian men vs. African Caribbean men}

Age-adjusted mean T, cFT and SHBG were lower in SA men when compared to AC men. However, these ethnic differences were no longer statistically significant in fully-adjusted models (Table 2 and Table S3).

\section{African Caribbean men vs. White European men}

Age-adjusted mean $\mathrm{LH}$ levels were higher in $\mathrm{AC}$ than in WE men but all other $\mathrm{RH}$ were similar. The ethnic differences in LH levels were no longer statistically significant in fullyadjusted models (Table 2 and Table S3).

\section{Age-adjusted and multivariable-adjusted associations between measures of adiposity} and male reproductive hormone levels within ethnic groups

Relationships between adiposity (BMI, WC or body fat) and RH differed within ethnic groups (Figures 2, 3 and 4). In SA men, an age-adjusted and multivariable-adjusted analysis showed that BMI was not related to $\mathrm{RH}$. In SA men, an age-adjusted analysis showed that WC had a weak negative relationship with $T$ and SHBG, and that \%body fat was negatively associated with T. However, in multivariable analysis, these age-adjusted estimates were no longer significant and only \%body fat was negatively associated with LH levels (Figure 4).

In contrast, in WE and AC men, BMI, WC and body fat showed strong negative relationships with T, cFT and SHBG in age-adjusted and fully-adjusted models in which the covariates were: age, frequent alcohol intake, smoking, IR and comorbidity burden.

Relationship of male reproductive hormone levels to insulin resistance within ethnic groups

In univariate analysis, HOMA-IR showed negative relationships with T and cFT in WE and in 
$A C$ men, and a negative relationship with LH in WE men. In contrast, in SA men HOMA-IR was not related to any $\mathrm{RH}$ (Table S4).

In multivariable-adjusted models, HOMA-IR was not associated with any $\mathrm{RH}$ within any ethnic group (Table S4; covariates: age, alcohol intake, smoking status, comorbidity and adiposity (WC, BMI or \%body fat)).

\section{$K$-fold cross-validation to assess robustness of results}

5-fold cross-validation showed that our linear regression analyses had good internal consistency, with similar differences in mean squared error (MSE) values across the folds and across the 3 ethnic groups (Tables S5, S6 and S7).

\section{Discussion}

We have shown that: 1) T and cFT levels were lower in SA men when compared to WE and AC men; 2) T levels were lower and LH levels were higher in SA compared to WE men after adjusting for confounders; 3 ) differences in cFT levels between SA and WE men could be explained by co-variables (i.e body fat); 4) $\mathrm{T}$ and cFT levels were not strongly related to adiposity (\%body fat, BMI and WC) in SA men while strong negative relationships were observed in WE and AC men. These findings have potential implications for the assessment of men with suspected hypogonadism and for understanding the mechanisms underlying these inter-ethnic differences.

\section{Prior studies}

Prior data are limited when comparing ethnic differences in $\mathrm{T}$ in men and to our knowledge there is no data on ethnic associations with $\mathrm{LH}$. Heald and co-workers studied $50 \mathrm{SA}$ Pakistani men, 55 WE men and $75 \mathrm{AC}^{\text {men }}{ }^{1}$ and showed that $\mathrm{T}$ was lower in SA men compared to other ethnic groups but these ethnic differences disappeared after adjusting for insulin, SHBG, waist hip ratio and height. Although this study was first to report these 
relationships, some limitations might have influenced the results: it had a relatively small sample size with limited ability to adjust for covariates; it used a $T$ immunoassay with suboptimal performance at low T levels when compared to LC-MS/MS methods ${ }^{21,22}$; it did not measure LH and their study did not report a standardized time at which serum samples were collected. Addressing these limitations, our study shows that in SA men the lower cFT, but not $\mathrm{T}$ levels, are explained by measured co-variables (i.e. body fat). Additional analysis revealed that these results did not differ after excluding men who used diabetes medications (data not shown).

Giton and colleagues reported higher T levels in AC men compared to WE men ${ }^{23}$. We showed numerically higher T levels in AC compared to WE men but this difference was not statistically significant (Table 1) and T levels were virtually identical after age-adjustment (Table 2). In addition, our study also reports cFT, and LH levels and our hormone data were adjusted for differences in IR and \% body fat - variables which differed between AC and WE men and could explain between-group differences in T levels.

There is limited data describing relationships between adiposity and $\mathrm{RH}$ in different ethnic groups. Shamin and co-workers studied 200 young and middle-aged SA men (aged 30 to 50 years) in Pakistan and showed that T was inversely related to both BMI and WC in an unadjusted cross-sectional analysis ${ }^{24}$. In contrast to these findings, we observed no significant relationship between $\mathrm{T}$ and $\mathrm{BMI}$ or WC in older SA men (predominantly of Pakistani extraction) after adjusting for confounders. The most likely explanation for the discrepancies is that Shamin and co-workers presented the results of a univariate analysis whereas our analysis was multivariable-adjusted. This explanation is supported by the observation that in our age-adjusted analysis WC was negatively related to $T$ and the statistical significance was lost after further adjusting for additional covariates. Another potential explanation is that our SA men were older (mean age 56 vs. 39 years) and the results could have been influenced by age-related loss of lean mass and increase in fat mass $^{4,25}$.

This article is protected by copyright. All rights reserved. 


\section{Physiological mechanisms underlying ethnic differences in male reproductive hormone levels}

We have shown that ethnic differences in adiposity appear to explain ethnic differences in cFT but not the ethnic differences in T. From a physiological perspective, the relationships with cFT are likely to be more important because this is the active hormone at the cellular level.

We found that body fat is more strongly related to cFT levels in WE men than in in SA men. The reason for this is unclear but perhaps our measures of adiposity in SA men are less representative of metabolically active visceral fat than in other ethnic groups ${ }^{26}$.

Our data suggest that IR-induced hypothalamic suppression of $\mathrm{LH}$ in SA men does not explain lower $\mathrm{T}$ levels in these men. As we have observed, higher levels of abdominal obesity are commonly seen in SA men, which is an indirect marker of visceral obesity and $I^{4}$. IR is known to have a negative impact on hypothalamic/pituitary function ${ }^{7}$. However, in SA men we observed higher LH levels rather than lower levels compared to WE men.

Another possibility is that the low $\mathrm{T}$ levels in SA men may be due to selective testicular resistance because of target organ resistance to insulin action - as suggested by a prior study showing that increasing $I R$ is associated with decreased Leydig cell responsiveness to gonadotropin stimulation, which would lead to increased LH levels ${ }^{27}$.

Comorbidity burden is another factor that could contribute to gonadal axis dysfunction in ageing men ${ }^{6}$ and may contribute to lower responsiveness of testicular Leydig cells to $\mathrm{LH}$ leading to low $\mathrm{T}^{28}$. However, we found that additional adjustment for comorbidity burden within our study did not explain the lower T observed in SA men.

\section{Strengths and limitations}

Our study has several strengths: first, the large sample size and comprehensive array of assessments allowed adjustment for several potential confounders - critically important because many of these variables are highly prevalent especially in SA men; second, we assessed LH in addition to T, cFT and SHBG adding insight into the feedback relationships

This article is protected by copyright. All rights reserved. 
in the HPT-axis; third, in a subset of participants, we included multiple measures of adiposity (BMI, WC or \%body fat) and confirmed their correlation with Dual-Energy X-ray Absorptiometry (DEXA) measurements of total body fat (Table S8); and finally, we used a highly accurate method (LC-MS/MS) to measure $\mathrm{T}$, which has important advantages over the radio-immunoassay ${ }^{21,22}$.

We acknowledge some limitations: first, this cross-sectional observational study was unable to assess temporal changes or implicate causality; second, hormones were measured on a single occasion; third, we were unable to assess testicular size; fourth, we were unable to assess the Androgen Receptor exon 1 CAG repeat length; fifth, we used an indirect measure of IR; sixth, estradiol (E2) levels obtained from LC-MS/MS were not available, and finally, we were unable to assess migratory status (previously related to $T$ in SA men $)^{29}$.

\section{Summary and conclusions}

We have shown that T and cFT levels were lower in SA men when compared to WE and AC men. After adjusting for confounders, T was lower and LH higher in SA compared to WE men. Differences in cFT levels between SA and WE men appear to be explained by body fat. $\mathrm{T}$ and $\mathrm{cFT}$ levels in SA men, were only weakly related to adiposity in contrast to the strong negative relationships observed in WE and AC men.

These findings require replication in larger studies in order to determine whether ethnic-specific reference ranges for T, cFT and LH might be appropriate, especially for SA men. When interpreting low or borderline low $\mathrm{T}$ and cFT results, measures of adiposity, such as $\mathrm{BMI}$, are more valuable in WE and $\mathrm{AC}$ than in SA men.

\section{Acknowledgements}

RJAHE is supported by a Biotechnology and Biological Sciences Research Council Doctoral Training Partnership (BBSRC-DTP) PhD-fellowship, and is grateful for receiving support from the Fundatie van de Vrijvrouwe van Renswoude and Scholten-Cordes 
scholarship foundations. All authors would like to thank the men who participated in the HUSERMET-project (10) and are grateful for funding of the HUSERMET project by the U.K. BBSRC (Grant number: BB/C519038/1) and U.K. Medical Research Council, with contributions from Astra-Zeneca and Glaxo SmithKline.

\section{Contributions by authors}

RJAHE, FCWW and MKR wrote the analysis plan for the study. BGK provided lab measurements required to perform the analysis. RJAHE, AS and SRP performed data cleaning. RJAHE performed the analysis. PSG, AM, GT, RG, FCWW and MKR supervised the analysis. RJAHE wrote the manuscript. AS, SRP, TWO, GT, RG, FCWW and MKR supervised the writing process.

\section{Role of the funding source}

None of the funding sources had a role in the study design, data collection, analysis performed or interpretation of the results obtained. The decision to submit the manuscript for publication was the decision of the corresponding author, which was in agreement with the fellow co-authors.

\section{References}

1. Heald, A.H., Ivison, F., Anderson, S.G., et al. (2003) Significant ethnic variation in total and free testosterone concentration. Clin Endocrinol (Oxf) 58, 262266

2. Kupelian V, Hayes FJ, Link CL, Rosen R, McKinlay JB (2008) Inverse association of testosterone and the metabolic syndrome in men is consistent across race and ethnic groups. J Clin Endocr Metab 93:3403-3410

3. Misra, A. \& Khurana, L. (2011) Obesity-related non-communicable diseases: South Asians vs White Caucasians. Int J Obes (Lond) 35, 167-187.

4. Tchernof, A. \& Despres, J.P. (2013) Pathophysiology of human visceral obesity: an update. Physiol Rev 93, 359-404.

5. Camacho, E.M., Huhtaniemi, I.T., O'Neill, T.W. et al. (2013) Age-associated changes in hypothalamic-pituitary-testicular function in middle-aged and older men are modified by weight change and lifestyle factors: longitudinal results from the European Male Ageing Study. Eur J Endocrinol 168, 445-455.

6. Wu, F.C., Tajar, A., Pye, S.R. et al. (2008) Hypothalamic-pituitary-testicular axis disruptions in older men are differentially linked to age and modifiable risk factors: the European Male Aging Study. J Clin Endocrinol Metab 93, 2737-2745. 
7. Veldhuis, J.D. (2013) Changes in pituitary function with ageing and implications for patient care. Nature Reviews Endocrinology 9, 205-215.

8. Antonio, L., Wu, F.C.W., O'Neill, T.W. et al. (2016) Low Free Testosterone Is Associated with Hypogonadal Signs and Symptoms in Men with Normal Total Testosterone. J Clin Endocrinol Metab 101, 2647-2657.

9. Misra, A. \& Vikram, N.K. (2004) Insulin resistance syndrome (metabolic syndrome) and obesity in Asian Indians: evidence and implications. Nutrition 20, 482-491.

10. Krentz, A.J. \& Bailey, C.J. (2005) Oral antidiabetic agents - Current role in type 2 diabetes mellitus. Drugs 65, 385-411.

11. Dunn, W.B., Lin, W., Broadhurst, D. et al. (2015) Molecular phenotyping of a UK population: defining the human serum metabolome. Metabolomics 11, 9-26.

12. Lee, D.M., O'Neill, T.W., Pye, S.R. et al. (2009) The European Male Ageing Study (EMAS): design, methods and recruitment. Int J Androl 32, 11-24.

13. Lee, D.M., Pye, S.R., Tajar, A. et al. (2013) Cohort profile: the European Male Ageing Study. Int J Epidemiol 42, 391-401.

14. Wu FC, Tajar A, Beynon JM, et al. (2010) Identification of late-onset hypogonadism in middle-aged and elderly men. The New England Journal of Medicine 363:123-135

15. Washburn, R.A., Smith, K.W., Jette, A.M. et al. (1993) The Physical-Activity Scale for the Elderly (PASE) - Development and Evaluation. Journal of Clinical Epidemiology 46, 153-162.

16. Matthews, D.R., Hosker, J.P., Rudenski, A.S. et al. (1985) Homeostasis Model Assessment - Insulin Resistance and Beta-Cell Function from Fasting Plasma-Glucose and Insulin Concentrations in Man. Diabetologia 28, 412-419.

17. Vermeulen, A., Stoica, T. \& Verdonck, L. (1971) The apparent free testosterone concentration, an index of androgenicity. J Clin Endocrinol Metab 33, 759-767.

18. Vermeulen, A., Verdonck, L. \& Kaufman, J.M. (1999) A critical evaluation of simple methods for the estimation of free testosterone in serum. J Clin Endocrinol Metab 84, 3666-3672.

19. Gallagher, L.M., Owen, L.J. \& Keevil, B.G. (2007) Simultaneous determination of androstenedione and testosterone in human serum by liquid chromatographytandem mass spectrometry. Annals of Clinical Biochemistry 44, 48-56.

20. Seni, G. \& Elder, J.F. (2010) Ensemble methods in data mining improving accuracy through combining predictions. In Synthesis lectures on data mining and knowledge discovery. Morgan \& Claypool Publishers, San Rafael, Calif., pp. 1 online resource (xvi, 108 p.).

21. Huhtaniemi, I.T., Tajar, A., Lee, D.M. et al. (2012) Comparison of serum testosterone and estradiol measurements in 3174 European men using platform immunoassay and mass spectrometry; relevance for the diagnostics in aging men. Eur J Endocrinol 166, 983-991.

22. Hsing, A.W., Stanczyk, F.Z., Belanger, A. et al. (2007) Reproducibility of serum sex steroid assays in men by RIA and mass spectrometry. Cancer Epidemiol Biomarkers Prev 16, 1004-1008.

23. Giton, F., Fiet, J., Cornu, J.N. et al. (2011) Serum sex steroids measured in middle-aged European and African-Caribbean men by gas chromatography-mass spectrometry. Eur J Endocrinol 165, 917-924. 
24. Shamim, M.O., Khan, F.M.A. \& Arshad, R. (2015) Association between serum total testosterone and Body Mass Index in middle aged healthy men. Pakistan Journal of Medical Sciences 31, 355-359.

25. Kuk, J.L., Saunders, T.J., Davidson, L.E. et al. (2009) Age-related changes in total and regional fat distribution. Ageing Res Rev 8, 339-348.

26. Lear, S.A., Humphries, K.H., Kohli, S. et al. (2007) The use of BMI and waist circumference as surrogates of body fat differs by ethnicity. Obesity 15, 2817-2824.

27. Pitteloud N, Hardin M, Dwyer AA, et al. (2005) Increasing insulin resistance is associated with a decrease in Leydig cell testosterone secretion in men. $J$ Clin Endocr Metab 90:2636-2641

28. Tajar, A., Forti, G., O'Neill, T.W. et al. (2010) Characteristics of Secondary, Primary, and Compensated Hypogonadism in Aging Men: Evidence from the European Male Ageing Study. J Clin Endocrinol Metab 95, 1810-1818.

29. Heald, A.H., Patel, J., Anderson, S.G. et al. (2007) Migration is associated with lower total, but not free testosterone levels in South Asian men. Clin Endocrinol (Oxf) 67, 651-655

Table 1. Comparison of clinical characteristics of older South Asian, White European and African Caribbean men

\begin{tabular}{|c|c|c|c|c|c|c|}
\hline Parameter & $\begin{array}{c}\text { South } \\
\text { Asian (SA) } \\
N=174\end{array}$ & $\begin{array}{c}\text { White } \\
\text { European } \\
\text { (WE) } \\
N=311\end{array}$ & $\begin{array}{c}\text { African } \\
\text { Caribbean } \\
\text { (AC) } \\
N=157\end{array}$ & $\begin{array}{c}p \text {-value } \\
\text { SA vs. } \\
\text { WE }\end{array}$ & $\begin{array}{c}p \text {-value } \\
\text { SA vs. AC }\end{array}$ & $\begin{array}{c}p \text {-value } \\
\text { WE vs. } \\
\text { AC }\end{array}$ \\
\hline Age, years & $55.9 \pm 0.8$ & $63.8 \pm 0.6$ & $53.0 \pm 0.8$ & $<.001$ & 0.041 & $<.001$ \\
\hline Height, $\mathrm{cm}$ & $170.2 \pm 0.5$ & $174.5 \pm 0.4$ & $173.5 \pm 0.5$ & $<.001$ & $<.001$ & 0.417 \\
\hline Body fat, $\%$ & $32.6 \pm 0.3$ & $28.9 \pm 0.3$ & $27.9 \pm 0.5$ & $<.001$ & $<.001$ & 0.180 \\
\hline BMl, $\mathrm{kg} / \mathrm{m}^{2}$ & $27.7 \pm 0.3$ & $27.5 \pm 0.2$ & $27.2 \pm 0.3$ & 1.000 & 0.906 & 1.000 \\
\hline $\begin{array}{l}\text { Waist circumference, } \\
\mathrm{cm}\end{array}$ & $99.6 \pm 0.8$ & $98.5 \pm 0.6$ & $92.5 \pm 0.9$ & 0.788 & $<.001$ & $<.001$ \\
\hline Calf circumference, $\mathrm{cm}$ & $32.8 \pm 0.3$ & $35.2 \pm 0.2$ & $33.0 \pm 0.3$ & $<.001$ & 1.000 & $<.001$ \\
\hline $\begin{array}{l}\text { Smoking (current), } \mathrm{n} \\
(\%)\end{array}$ & $26(29)$ & $22(7)$ & $37(41)$ & $<.050$ & $>.050$ & $<.050$ \\
\hline $\begin{array}{l}\text { Frequent alcohol } \\
\text { intake, } \mathrm{n}(\%)\end{array}$ & $2(1)$ & $81(26)$ & $28(18)$ & $<.050$ & $<.050$ & $>.050$ \\
\hline PASE score & $160 \pm 8$ & $194 \pm 5$ & $224 \pm 11$ & 0.002 & $<.001$ & 0.016 \\
\hline $\begin{array}{l}\text { Fasting plasma } \\
\text { glucose, } \mathrm{mmol} / \mathrm{L}\end{array}$ & $6.3 \pm 0.1$ & $5.5 \pm 0.1$ & $5.5 \pm 0.1$ & $<.001$ & $<.001$ & 1.000 \\
\hline HOMA-IR & $5.7 \pm 0.6$ & $4.2 \pm 0.6$ & $3.1 \pm 0.3$ & 0.851 & 0.031 & 0.877 \\
\hline Diabetes, n (\%) & $50(33)$ & $30(10)$ & $16(11)$ & $<.050$ & $<.050$ & $>.050$ \\
\hline Poor health, n (\%) & $51(29)$ & $30(10)$ & $28(18)$ & $<.050$ & $<.050$ & $<.050$ \\
\hline $\begin{array}{l}1 \text { or more chronic } \\
\text { illness, } n(\%)\end{array}$ & $105(60)$ & $157(51)$ & $56(36)$ & $>.050$ & $<.050$ & $<.050$ \\
\hline $\begin{array}{l}\text { Total testosterone, } \\
\mathrm{nmol} / \mathrm{L}\end{array}$ & $14.2 \pm 0.4$ & $16.8 \pm 0.3$ & $17.6 \pm 0.5$ & $<.001$ & $<.001$ & 0.460 \\
\hline $\begin{array}{l}\text { Free testosterone, } \\
\mathrm{pmol} / \mathrm{L}\end{array}$ & $294 \pm 8$ & $296 \pm 5$ & $335 \pm 8$ & 1.000 & 0.001 & $<.001$ \\
\hline SHBG, $\mathrm{nmol} / \mathrm{L}$ & $32.5 \pm 1.2$ & $42.3 \pm 1.0$ & $38.6 \pm 1.2$ & $<.001$ & 0.003 & 0.066 \\
\hline $\mathrm{LH}, \mathrm{U} / \mathrm{L}$ & $6.8 \pm 0.3$ & $6.1 \pm 0.3$ & $6.1 \pm 0.2$ & 0.263 & 0.520 & 1.000 \\
\hline
\end{tabular}

This article is protected by copyright. All rights reserved. 
Table 2: Age-adjusted male reproductive hormone levels in older South Asian, White European and African Caribbean men

\begin{tabular}{|c|c|c|c|c|c|c|c|c|c|c|c|c|c|c|c|c|c|c|c|c|c|}
\hline \multirow[t]{2}{*}{$\begin{array}{l}\text { Para } \\
\text { meter }\end{array}$} & \multirow{2}{*}{$\begin{array}{c}\text { Sou } \\
\text { th } \\
\text { Asia } \\
n \\
(\mathrm{SA} \\
\text { ) } \\
\\
\\
N=1 \\
74\end{array}$} & \multirow{2}{*}{$\begin{array}{c}\text { Whit } \\
\text { e } \\
\text { Euro } \\
\text { pea } \\
n \\
\text { (WE } \\
\text { ) } \\
\\
N=3 \\
11\end{array}$} & \multirow{2}{*}{$\begin{array}{c}\text { Afric } \\
\text { an } \\
\text { Cari } \\
\text { bbea } \\
n \\
\text { (AC) } \\
\\
N=1 \\
57\end{array}$} & \multicolumn{3}{|c|}{$\begin{array}{c}\text { Model } 1 \\
\text { Includes age }\end{array}$} & \multicolumn{3}{|c|}{$\begin{array}{c}\text { Model } 2 \\
\text { Includes age } \\
\text { and \%body fat }\end{array}$} & \multicolumn{3}{|c|}{$\begin{array}{c}\text { Model } 3 \\
\text { Includes age } \\
\text { and HOMA-IR }\end{array}$} & \multicolumn{3}{|c|}{$\begin{array}{c}\text { Model } 4 \\
\text { Includes age, } \\
\text { \%body fat and } \\
\text { HOMA-IR }\end{array}$} & \multicolumn{3}{|c|}{$\begin{array}{c}\text { Model } 5 \\
\text { Includes age, } \\
\text { alcohol intake, } \\
\text { smoking, } \\
\text { \%body fat, } \\
\text { HOMA-IR }\end{array}$} & \multicolumn{3}{|c|}{$\begin{array}{c}\text { Model } 6 \\
\text { Includes age, } \\
\text { alcohol intake, } \\
\text { smoking, } \\
\text { \%body fat, } \\
\text { HOMA-IR and } \\
\text { comorbidity } \\
\text { burden }\end{array}$} \\
\hline & & & & $\begin{array}{l}\text { S } \\
\text { A } \\
\text { Vs } \\
\dot{W} \\
\text { E }\end{array}$ & $\begin{array}{c}\mathrm{S} \\
\mathrm{A} \\
\text { Vs } \\
\dot{\mathrm{A}} \\
\mathrm{C}\end{array}$ & $\begin{array}{l}\text { W } \\
\mathrm{E} \\
\text { vs } \\
\dot{\mathrm{A}} \\
\mathrm{C}\end{array}$ & $\begin{array}{l}\mathrm{S} \\
\mathrm{A} \\
v S\end{array}$ & $\begin{array}{l}\text { S } \\
\text { A } \\
\text { vs } \\
\dot{A} \\
\text { C }\end{array}$ & $\begin{array}{l}\text { W } \\
\mathrm{E} \\
\text { vs } \\
\dot{\mathrm{A}} \\
\mathrm{C}\end{array}$ & $\begin{array}{l}\mathrm{S} \\
\mathrm{A} \\
\text { vs }\end{array}$ & $\begin{array}{l}\mathrm{S} \\
\mathrm{A} \\
v s \\
\dot{\mathrm{A}} \\
\mathrm{C}\end{array}$ & $\begin{array}{c}\text { W } \\
\mathrm{E} \\
\text { vs } \\
\text { A } \\
\mathrm{C}\end{array}$ & $\begin{array}{l}\mathrm{S} \\
\mathrm{A} \\
v \mathrm{~S}\end{array}$ & $\begin{array}{l}\mathrm{S} \\
\mathrm{A} \\
v s \\
\dot{\mathrm{A}} \\
\mathrm{C}\end{array}$ & $\begin{array}{l}\text { W } \\
\mathrm{E} \\
\text { vs } \\
\dot{\mathrm{A}} \\
\mathrm{C}\end{array}$ & $\begin{array}{l}\text { S } \\
\text { A } \\
\text { vs } \\
\dot{W} \\
\text { E }\end{array}$ & $\begin{array}{l}\mathrm{S} \\
\mathrm{A} \\
v s \\
\dot{\mathrm{A}} \\
\mathrm{C}\end{array}$ & $\begin{array}{c}\text { W } \\
\mathrm{E} \\
\text { vs } \\
\dot{\mathrm{A}} \\
\mathrm{C}\end{array}$ & $\begin{array}{l}\mathrm{S} \\
\mathrm{A} \\
\text { vs }\end{array}$ & $\begin{array}{l}\text { S } \\
\text { A } \\
v S\end{array}$ & $\begin{array}{l}\text { W } \\
\mathrm{E} \\
\text { vs } \\
\dot{\mathrm{A}} \\
\mathrm{C}\end{array}$ \\
\hline \multicolumn{22}{|c|}{ All men } \\
\hline $\begin{array}{l}\text { Total } \\
\text { testos } \\
\text { terone } \\
\text { nmol/ } \\
\text { L }\end{array}$ & $\begin{array}{l}14.0 \\
\pm 0.4\end{array}$ & $\begin{array}{l}17.1 \\
\pm 0.3\end{array}$ & $\begin{array}{l}17.2 \\
\pm 0.5\end{array}$ & $\begin{array}{c}<. \\
00 \\
1\end{array}$ & $\begin{array}{c}<. \\
00 \\
1\end{array}$ & $\begin{array}{c}1 . \\
00 \\
0\end{array}$ & $\begin{array}{c}0 . \\
00 \\
3\end{array}$ & $\begin{array}{c}0 . \\
02 \\
9\end{array}$ & $\begin{array}{c}1 . \\
00 \\
0\end{array}$ & $\begin{array}{c}<. \\
00 \\
1\end{array}$ & $\begin{array}{c}<. \\
00 \\
1\end{array}$ & $\begin{array}{c}1 . \\
00 \\
0\end{array}$ & $\begin{array}{c}0 . \\
00 \\
4\end{array}$ & $\begin{array}{c}0 . \\
02 \\
2\end{array}$ & $\begin{array}{c}1 . \\
00 \\
0\end{array}$ & $\begin{array}{c}0 . \\
01 \\
8\end{array}$ & $\begin{array}{c}0 . \\
90 \\
7\end{array}$ & $\begin{array}{c}0 . \\
28 \\
8\end{array}$ & $\begin{array}{c}0 . \\
03 \\
5\end{array}$ & $\begin{array}{c}1 . \\
00 \\
0\end{array}$ & $\begin{array}{c}0 . \\
32 \\
3\end{array}$ \\
\hline $\begin{array}{l}\text { Free } \\
\text { testos } \\
\text { terone } \\
\text { pmol/ } \\
\text { L }\end{array}$ & $\begin{array}{c}283 \\
\pm 7\end{array}$ & $\begin{array}{l}313 \\
\pm 5\end{array}$ & $\begin{array}{c}314 \pm \\
8\end{array}$ & $\begin{array}{c}0 . \\
00 \\
2\end{array}$ & $\begin{array}{c}0 . \\
00 \\
6\end{array}$ & $\begin{array}{c}1 . \\
00 \\
0\end{array}$ & $\begin{array}{l}0 . \\
26 \\
2\end{array}$ & $\begin{array}{c}0 . \\
51 \\
0\end{array}$ & $\begin{array}{c}1 . \\
00 \\
0\end{array}$ & $\begin{array}{c}0 . \\
00 \\
4\end{array}$ & $\begin{array}{c}0 . \\
01 \\
1\end{array}$ & $\begin{array}{c}1 . \\
00 \\
0\end{array}$ & $\begin{array}{c}0 . \\
20 \\
4\end{array}$ & $\begin{array}{c}0 . \\
47 \\
0\end{array}$ & $\begin{array}{c}1 . \\
00 \\
0\end{array}$ & $\begin{array}{c}0 . \\
21 \\
2\end{array}$ & $\begin{array}{c}1 . \\
00 \\
0\end{array}$ & $\begin{array}{c}0 . \\
39 \\
5\end{array}$ & $\begin{array}{l}0 . \\
28 \\
3\end{array}$ & $\begin{array}{l}1 . \\
00 \\
0\end{array}$ & $\begin{array}{c}0 . \\
42 \\
8\end{array}$ \\
\hline $\begin{array}{l}\text { SHBG } \\
\text { nmol/ } \\
\mathrm{L}\end{array}$ & $\begin{array}{l}34.2 \\
\pm 1.2\end{array}$ & $\begin{array}{l}39.8 \\
\pm 0.9\end{array}$ & $\begin{array}{l}41.7 \\
\pm 1.3\end{array}$ & $\begin{array}{c}0 . \\
00 \\
1\end{array}$ & $\begin{array}{c}<. \\
00 \\
1\end{array}$ & $\begin{array}{c}0 . \\
78 \\
3\end{array}$ & $\begin{array}{c}0 . \\
27 \\
6\end{array}$ & $\begin{array}{l}0 . \\
08 \\
6\end{array}$ & $\begin{array}{c}1 . \\
00 \\
0\end{array}$ & $\begin{array}{c}0 . \\
00 \\
5\end{array}$ & $\begin{array}{c}<. \\
00 \\
1\end{array}$ & $\begin{array}{c}0 . \\
42 \\
5\end{array}$ & $\begin{array}{c}0 . \\
40 \\
4\end{array}$ & $\begin{array}{c}0 . \\
06 \\
1\end{array}$ & $\begin{array}{c}0 . \\
81 \\
3\end{array}$ & $\begin{array}{c}1 . \\
00 \\
0\end{array}$ & $\begin{array}{c}1 . \\
00 \\
0\end{array}$ & $\begin{array}{c}1 . \\
00 \\
0\end{array}$ & $\begin{array}{l}1 . \\
00 \\
0\end{array}$ & $\begin{array}{l}1 . \\
00 \\
0\end{array}$ & $\begin{array}{c}1 . \\
00 \\
0\end{array}$ \\
\hline $\begin{array}{l}\mathrm{LH}, \\
\mathrm{U} / \mathrm{L}\end{array}$ & $\begin{array}{l}7.1 \pm \\
0.3\end{array}$ & $\begin{array}{c}5.6 \pm \\
0.2\end{array}$ & $\begin{array}{l}6.8 \pm \\
0.3\end{array}$ & $\begin{array}{c}<. \\
00 \\
1\end{array}$ & $\begin{array}{c}1 . \\
00 \\
0\end{array}$ & $\begin{array}{c}0 . \\
01 \\
4\end{array}$ & $\begin{array}{c}<. \\
00 \\
1\end{array}$ & $\begin{array}{c}0 . \\
69 \\
3\end{array}$ & $\begin{array}{c}0 . \\
03 \\
4\end{array}$ & $\begin{array}{c}0 . \\
00 \\
1\end{array}$ & $\begin{array}{c}1 . \\
00 \\
0\end{array}$ & $\begin{array}{c}0 . \\
01 \\
0\end{array}$ & $\begin{array}{c}<. \\
00 \\
1\end{array}$ & $\begin{array}{c}0 . \\
59 \\
1\end{array}$ & $\begin{array}{c}0 . \\
02 \\
8\end{array}$ & $\begin{array}{c}0 . \\
00 \\
8\end{array}$ & $\begin{array}{c}0 . \\
38 \\
7\end{array}$ & $\begin{array}{c}0 . \\
49 \\
2\end{array}$ & $\begin{array}{c}0 . \\
01 \\
4\end{array}$ & $\begin{array}{c}0 . \\
47 \\
0\end{array}$ & $\begin{array}{c}0 . \\
54 \\
0\end{array}$ \\
\hline
\end{tabular}

Group comparisons $P$ values were calculated using analyses of covariance

Multivariable-adjusted models

Model 1: adjusted for age

Model 2: adjusted for age and \% body fat

Model 3: adjusted for age and HOMA-IR

Model 4: adjusted for age, \% body fat and HOMA-IR

Model 5: adjusted for age, frequent alcohol intake, smoking (current), body fat (\%), HOMA-IR

Model 6: adjusted for age, frequent alcohol intake, smoking (current), body fat (\%), HOMA-IR and comorbidity burden ( $\geq 1$ comorbidities)

Abbreviations: N, sample size; SHBG, Sex Hormone-Binding Globulin; LH, Luteinizing Hormone

This article is protected by copyright. All rights reserved. 
Figure 1.

Flowchart of Participants

SA, South Asian

WE, White European

AC, African Caribbean

$\mathbf{n = 7 0 9}$ men recruited in total

\begin{tabular}{|c|c|c|c|c|c|}
\hline $\begin{array}{l}\text { South } \\
\text { Asian } \\
n=180\end{array}$ & $\begin{array}{c}\text { White } \\
\text { European } \\
n=328\end{array}$ & $\begin{array}{c}\text { African } \\
\text { Caribbean } \\
n=166\end{array}$ & $\begin{array}{l}\text { Other } \\
n=25\end{array}$ & $\begin{array}{c}\text { Missing } \\
n=10\end{array}$ & $\begin{array}{l}\text { Exclusions } \\
\mathrm{n}=2 \mathrm{AC} \text { men with BMI } \\
>60 \mathrm{~kg} / \mathrm{m}^{2} \\
\mathrm{n}=4 \mathrm{SA} \text { men with } \\
\text { testicular disorder } \\
\mathrm{n}=1 \text { WE men with } \\
\text { testicular disorder } \\
\mathrm{n}=1 \text { AC men with } \\
\text { testicular disorder } \\
\mathrm{n}=2 \text { SA men on HPT- } \\
\text { axis affecting drugs } \\
\mathrm{n}=16 \text { WE men on } \\
\text { HPT-axis affecting } \\
\text { drugs } \\
\mathrm{n}=6 \text { AC men on HPT- } \\
\text { axis affecting drugs } \\
\mathrm{n}=1 \text { "Other" men on } \\
\text { HPT-axis affecting } \\
\text { drugs }\end{array}$ \\
\hline \multicolumn{5}{|c|}{$\mathrm{n}=642$ men in the analytical sample } & \multirow[b]{2}{*}{$\begin{array}{l}\text { Exclusions } \\
\text { Excluded "Other" } \\
\text { ethnicity group } \\
\text { Excluded "Missing" } \\
\text { ethnicity group }\end{array}$} \\
\hline & & & & & \\
\hline \multicolumn{2}{|c|}{$\begin{array}{l}\text { South } \\
\text { Asian } \\
n=174\end{array}$} & $\begin{array}{c}\text { White } \\
\text { European } \\
n=311\end{array}$ & & $\begin{array}{l}\text { African } \\
\text { aribbean } \\
n=157\end{array}$ & \\
\hline
\end{tabular}

This article is protected by copyright. All rights reserved. 

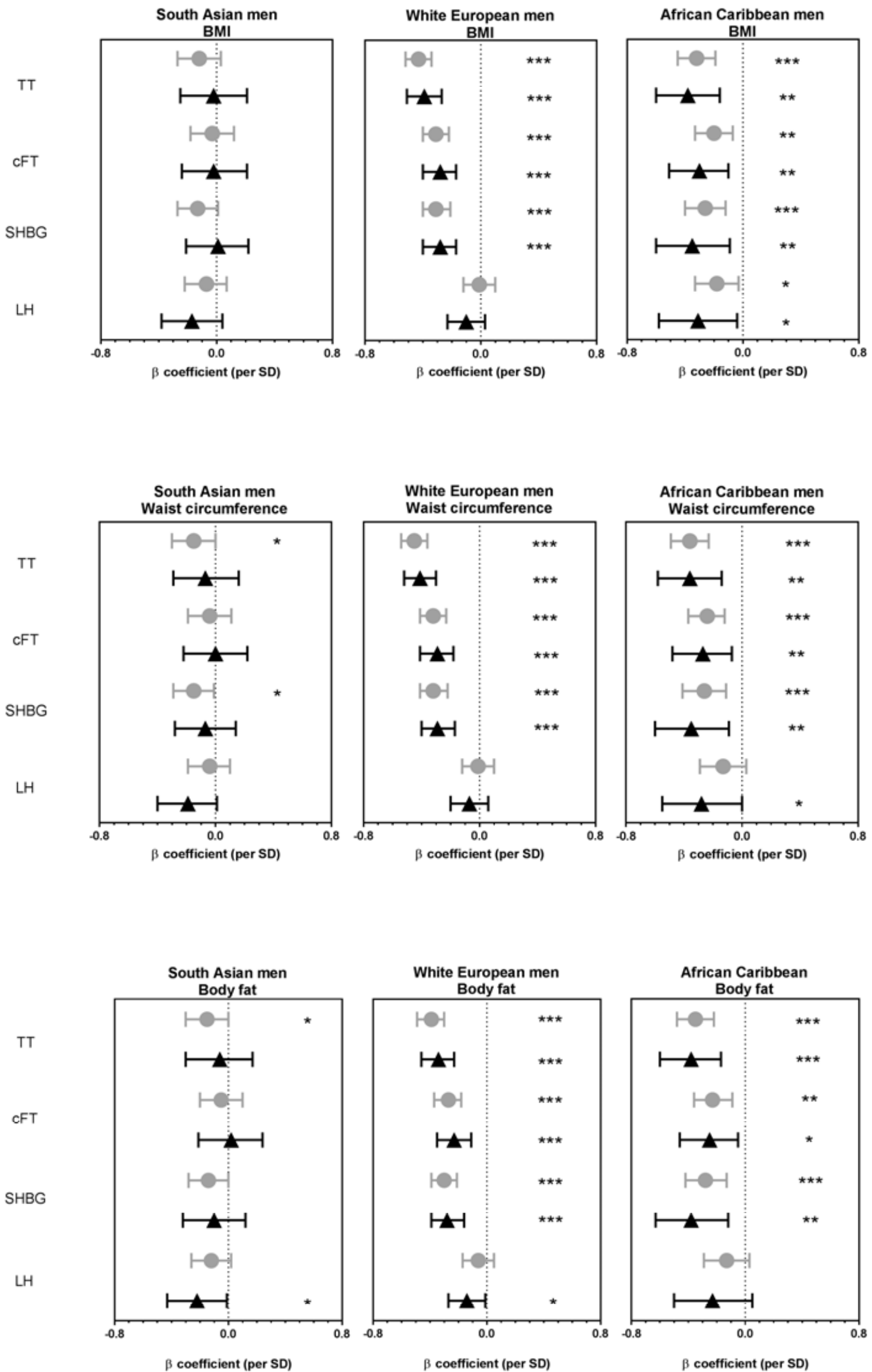

This article is protected by copyright. All rights reserved. 


\section{Figure outline}

\section{R.J.A.H. Eendebak et al., Ethnic differences in male reproductive hormones and relationships with adiposity and insulin resistance in older men}

Figure 2: Age-adjusted and multivariable-adjusted relationships between body mass index (BMI) and male reproductive hormone levels in older South Asian, White European and African Caribbean men

Legend: Circles represent beta coefficients from age-adjusted linear regression models using BMI as a predictor and triangles represent beta coefficients from fully adjusted linear regression models using $\mathrm{BMI}$ as a predictor and study age, alcohol intake, smoking, HOMA-IR, and comorbidity burden as covariates. The strength and directions of the associations are depicted by the beta coefficients and the $95 \%$ confidence intervals, respectively. The statistical significance of the associations are provided by the stars, whereby * star indicates $\mathrm{P}<0.05$, ${ }^{* *}$ indicate $\mathrm{P}<0.01$ and ${ }^{* *}$ indicate $\mathrm{P}<0.001$.

Figure 3: Age-adjusted and multivariable-adjusted relationships between waist circumference and male reproductive hormone levels in older South Asian, White European and African Caribbean men

Legend: Circles represent beta coefficients from age-adjusted linear regression models using waist circumference as a predictor and triangles represent beta coefficients from fully adjusted linear regression models using waist circumference as a predictor and study age, alcohol intake, smoking, HOMA-IR and comorbidity burden as covariates. The strength and directions of the associations are depicted by the beta coefficients and the $95 \%$ confidence intervals, respectively. The statistical significance of the associations are provided by the stars, whereby * indicates $\mathrm{P}<0.05$, ${ }^{*}$ indicate $\mathrm{P}<0.01$ and $^{* * *}$ indicate $\mathrm{P}<0.001$

Figure 4: Age-adjusted and multivariable-adjusted relationships between body fat (\%) and male reproductive hormone levels in older South Asian, White European and African Caribbean men

Legend: Circles represent beta coefficients from age-adjusted linear regression models using body fat $(\%)$ as a predictor and triangles represent beta coefficients from fully adjusted linear regression models using body fat (\%) as a predictor and study age, alcohol intake, smoking, HOMA-IR and comorbidity burden as covariates. The strength and directions of the associations are depicted by the beta coefficients and the $95 \%$ confidence intervals, respectively. The statistical significance of the associations are provided by the stars, whereby * indicates $\mathrm{P}<0.05$, ** indicate $\mathrm{P}<0.01$ and *** indicate $\mathrm{P}<0.001$

This article is protected by copyright. All rights reserved. 